\title{
Revendo Paulo Freire: Uma Introdução
}

\section{Revisiting Paulo Freire: An Introduction}

\author{
A D I LSON C T T E L L T \\ Universidade de São Paulo, Programa de Pós-Graduação em Ciências da Comunicação. São Paulo, SP - Brasil
}

A NA CRISTINA SUZTNA ${ }^{b}$

Loughborough University London, Institute for Media and Creative Industries. Londres, Reino Unido

THOMAS TUFTE ${ }^{\mathrm{c}}$

Loughborough University London, Institute for Media and Creative Industries. Londres, Reino Unido

University of the Free State, Department of Communication Science. Bloemfontein - Free State, África do Sul

\section{CONTEXTO}

$\Lambda$

REVISTA MATRIZes lança este número especial dedicado ao centenário do nascimento de Paulo Freire (1921-1998). Os textos a serem ses, o que atesta o vigor e a atualidade da contribuição teórico-prática deste pernambucano cidadão do mundo. Tais análises intentam verificar quais as contribuições do pensamento freiriano para o campo da comunicação, da educação e do desenvolvimento da sociedade civil, considerando as realidades locais em que foram mobilizadas.

Apenas um dos livros de Freire (1969/1983) aborda diretamente e de modo mais amplo o âmbito da comunicação; trata-se de Extensão ou Comunicação?, publicado em 1969, originalmente em espanhol, durante o exílio do educador no Chile. Essa obra se tornou referencial importante para os estudos e práticas de comunicação participativa no mundo, e foi decisiva para a revisão dos modelos difusionistas (Peruzzo, 2020b), que tomavam a comunicação como ferramenta para orientar a reprodução de modelos considerados modernos e desenvolvidos, sem atentar para as experiências e conhecimentos locais.

De maneira mais ampla, porém, a transversalidade da comunicação na perspectiva pedagógica de Freire, pode ser discutida a partir de, pelo menos, três direções. A primeira associa linguagem, educação e comunicação. A segunda vincula a educação à mobilização popular e, mais abertamente a processos de engajamento político. A terceira decorre da própria postura crítica freiriana em relação à mídia. Essas três inflexões serão discutidas com mais detalhes ao longo
Professor titular no Departamento de Comunicações e Artes e do Programa de Pós-Graduação em Ciências da Comunicação da Universidade de São Paulo. É coordenador do Grupo de Pesquisa MECOM e bolsista 1B do CNPq. Orcid: https://orcid. org/0000-0002-0838-9917. E-mail: citelli@uol.com.br

${ }^{\mathrm{b}}$ Professora e pesquisadora do Institute for Media and Creative Industries da Loughborough University London. Editora do livro The Evolution of Popular Communication in Latin America (Palgrave, 2021). Orcid: https://orcid.org/00000003-3559-6513. E-mail: a.suzina@lboro.ac.uk

${ }^{c}$ Diretor do Institute for Media and Creative Industries da Loughborough University London e professor extraordinário da University of The Free State, África do Sul. É membro da Academia Europaea. Orcid: https://orcid. org/0000-0003-3253-8481. E-mail: t.tufte@lboro.ac.uk 
do material reunido nesta edição de MATRIZes, logo depois desta Introdução, que busca situar as linhas de força que acompanham os artigos e posiciona Paulo Freire como um dos mais importantes pensadores do século XX.

\section{EDUCADOR MILITANTE}

Pensador da educação libertadora, Paulo Freire tem a sua obra traduzida em mais de vinte línguas, entre elas o urtu e o árabe, deixando funda marca em projetos de alfabetização cujos exemplos podem ser reconhecidos em Angicos (Pernambuco) ou Natal (Rio Grande do Norte), no Brasil, até Guiné-Bissau, Cabo Verde e Angola, na África.

Os envolvimentos de Freire ocorreram, também, na organização de projetos nacionais e internacionais e mesmo na administração pública, a se ver o trabalho junto ao Instituto de Desenvolvimento da Agricultura (Indap), no Chile; ao Conselho Mundial das Igrejas (CMI), em Genebra; ao Instituto de Ação Cultural (Idac), fundado em 1971 na Suíça, juntamente com Elza Freire, Miguel e Rosiska Darcy de Oliveira, Claudius Ceccon e outros; à Secretaria de Educação da cidade de São Paulo (1989-1991). Nesse caso, assumindo a tarefa de gerir um complexo sistema que havia sido sucateado na administração anterior, do prefeito Jânio da Silva Quadros. Tratando-se, agora, de recuperar, sob o ponto de vista administrativo, pedagógico e de valorização do corpo funcional, uma rede de ensino formal composta por 629 escolas, 720 mil alunos e 39.614 docentes. A cidade possuía, em 1989, 9,6 milhões de habitantes e 1,2 milhões de pessoas analfabetas acima dos 14 anos.

Esta rica trajetória teórico-prática compõe parte do perfil militante marcado pela vontade de transformação do mundo que caracterizou a vida e a obra de Paulo Freire. Como resumiu Pierre Furter (1967), na aba da apresentação do livro Educação como Prática da Liberdade:

Uma educação como prática da liberdade só poderá se realizar plenamente numa sociedade onde existem as condições econômicas, sociais e políticas de uma existência em liberdade. Por consequência e porque não pode haver renovação pedagógica sem uma renovação da sociedade global, as exigências pedagógicas de Paulo Freire o levaram também a assumir uma posição política.

A sua identificação com os oprimidos é demais conhecida e o levou a ser perseguido pela ditadura militar instituída no Brasil em 1964, resultando em quase 15 anos de exílio por inúmeros países. Em anos recentes, sobretudo com o advento do governo Bolsonaro e o seu ataque às instituições democráticas, 
à cultura, às artes e à educação, vivemos um paradoxo: enquanto o nome de Freire é crescentemente lembrado, tendo a sua obra reconhecida e trabalhada em várias partes do mundo, no Brasil, passou ela a ser objeto de sistemática desconstrução. E ele é acusado, paradoxalmente, por defender uma escola voltada à formação da cidadania e do espírito crítico, propósitos todos, por evidente, em franca colisão com regimes de extrema direita, satisfeitos com a educação bancária, transmissivista, monológica.

\section{TRÊS DIMENSÕES DO PENSAMENTO DE FREIRE}

O projeto freiriano pode ser considerado à luz de três grandes dimensões integradas: política-ideológica, metodológica, humanista. É o que será encontrado nos seus escritos e nas ações que implementou, dentre as quais inscrevem-se o Movimento de Educação de Base (MEB) até o engajamento nas lutas anticolonialistas em África.

\section{Desafio político-ideológico}

Há uma visão de mundo freiriana articulada em duas frentes: o catolicismo progressista expandido do concílio Vaticano II, juntamente com os nomes de Theillard de Chardin, Emmanuel Mounier, Jacques Maritain e Alceu Amoroso Lima, e o marxismo, cuja linhagem se expande para pensadores a incluírem Lukács e Lucien Goldman. Neste conjunto de influências, a presença do Instituto Superior de Estudos Brasileiros (Iseb) - 1955/1964 -, sobretudo através do filósofo Álvaro Vieira Pinto, marcará os textos de Paulo Freire.

Tal abertura teórico-prática, com recorte à esquerda, pode ser acompanhada desde os primeiros escritos pelos fins dos anos 1950 até a Pedagogia do Oprimido (Freire, 1968/2005) e trabalhos subsequentes. O que comparece nesta trajetória é o envolvimento com os objetivos de pensar os projetos de nação, trazendo, no caso brasileiro, o elemento popular para a cena principal de um país que se afirmava entre o desenvolvimentismo juscelinista e as lutas pelas reformas de base impulsionadas no curto mandato de João Goulart. A riqueza intelectual, política, artística daqueles finais dos anos 1950 até a implantação da ditadura, em 1964, compunha o quadro de fundo no qual vicejou a presença freiriana. Naquele cenário efervescente, alfabetizar implicava promover dois movimentos: o acesso à palavra escrita, ao código verbal e todas as consequências daí decorrentes, e o direito de o cidadão e da cidadã de participarem ativamente na vida do país: o voto consciente, o acesso ao poder do verbo, o reconhecimento do lugar no discurso. 
${ }^{1}$ Esses aspectos do trabalho de Freire inspiraram de forma bastante profunda uma corrente epistemológica do campo da comunicação, chamada na América Latina de comunicação popular (Peruzzo, 2020a; Suzina, 2021) e com equivalentes baseados nos mesmos princípios, como a comunicação cidadã (Rodríguez, 2001), a comunicação radical (Downing et al., 2001) e a comunicação para a mudança social (Gumucio-Dagron \& Tufte, 2006; Tufte 2017).
Em variações que seguem os respectivos contextos nacionais, o desafio reaparece no Chile, que prometia maior participação popular, com o advento do governo Eduardo Frei Montalva (1964-1970), período no qual o exilado em Santiago, Paulo Freire, participa da implantação de programas de educação junto às populações campesinas, no Indap - experiência decisiva para a produção do livro Extensão ou Comunicação? (Freire, 1969/1983). O motivo retorna no complexo programa de alfabetização levado a termo junto aos países africanos saídos do jugo colonial português e marcados por grande pluralidade linguística, em muitos casos de tradição ágrafa.

Ou seja, olhada no conjunto, a obra freiriana encontra-se fundamentalmente calcada em uma perspectiva política de transformação social - sendo a educação e a alfabetização partes deste esforço e a comunicação sua ontologia e ideologicamente aderente ao campo popular-progressista, no interior do qual devem ser forjadas as imagens e representações capazes de se antepor e transcender o ideário dos opressores.

\section{Questão de método}

É no interior dessa opção política que se pode entender os ajustes traduzidos no chamado método Paulo Freire. Vale dizer, a alfabetização de adultos, conforme a experiência de Angicos, no formato das quarenta horas de duração; a escolha das palavras geradoras; os mecanismos de codificação e descodificação; a organização dos círculos de cultura; o domínio da palavra e suas implicações nos jogos de poder, a importância do diálogo etc. O que se intenta, no fundo, são processos formativos da consciência, nos quais os sujeitos reconhecem o seu lugar no mundo e dele participam em busca das transformações que miram uma sociedade mais justa e igualitária ${ }^{1}$.

Como apontam vários estudiosos, a questão metodológica em Paulo Freire não é a da formatação engessada de determinações, roteiros, receituários para se resolver algum problema, senão o de uma construção coletiva garantida por procedimentos que asseguram a realização de certo propósito. Neste aspecto, o método em causa não implica ajuntamento eclético dirigido apenas a uma eficácia técnica pedagógica, mas visa, basicamente, à elaboração de compromissos com os sujeitos em aprendizagem, cujo propósito último é o encontro da consciência libertadora. Ou, nos termos de Ernani Maria Fiori (1968/2005, p. 10):

Ao objetivar o seu mundo, o alfabetizando nele reencontra-se com os outros e nos outros, companheiros do seu pequeno "círculo de cultura". Encontram-se e reencontram-se todos no mesmo mundo comum e, da coincidência das intenções 
que o objetivam, ex-surge a comunicação, o diálogo que criticiza e promove os participantes do círculo. . . No círculo de cultura, a rigor, não se ensina, aprende-se em "reciprocidade de consciências"; não há professor, há um coordenador que tem por função dar as informações solicitadas pelos respectivos participantes e propiciar condições favoráveis à dinâmica do grupo, reduzindo ao mínimo sua intervenção direta no curso do diálogo.

Deste modo, se o chamado método Paulo Freire considera a sistematização de procedimentos, vem ele no bojo de uma concepção de mundo e das relações horizontais que devem animar os vínculos e as trocas entre educadores-educandos, afinal: "ninguém educa ninguém, ninguém educa a si mesmo, os homens se educam entre si, mediatizados pelo mundo" (Freire, 1968/2005, p. 78).

\section{Inflexão humanista}

Pouco ou nada faria sentido na construção dos projetos nacionais ou na implementação de métodos educadores caso deles estivesse apartada uma atitude de respeito aos seres humanos, aqui compreendida a trajetória de superação das imposturas alienantes, do direito à liberdade e às condições dignas de existência. No projeto teórico-prático de Paulo Freire é reiterada a adesão ao humanismo emancipador, no qual os sujeitos deixam de ser explorados em suas relações de trabalho, integrando-se nos circuitos afetivos que permitem o reconhecimento do outro, o exercício da alteridade, a desinterdição da palavra dos subalternizados.

É compreensível ler-se a Pedagogia do Oprimido (Freire, 1968/2005) à luz de uma ação político-educadora votada ao humanismo radical, pelo que se enfatizam as relações intersubjetivas e o diálogo enquanto elementos necessários para a construção das sociabilidades transformadoras. Ao longo dos seus livros, termos novos, de grande carga afetiva, vão sendo criados, como se houvesse um esforço linguístico de afirmar o sentido de humanidade que deve presidir os vínculos entre os sujeitos e garantir os processos de comunicabilidade: boniteza, admiração, amorosidade, inacabamento/inconclusão (das pessoas), re-admirar, existenciar, esperançar etc. ${ }^{2}$

Ademais, os nexos entre educação/formação/democracia dizem respeito, em última análise, à preocupação com a dignidade na vida dos homens e mulheres: "a desconsideração total pela formação integral do ser humano, a sua redução a puro treino fortalece a maneira autoritária de fala de cima para baixo a que falta, por isso mesmo, a intenção de sua democratização no falar com" (Freire, 1996/2006, p. 116). Ou ainda: "é na diretividade da educação, esta vocação que ela tem, como ação especificamente humana,
${ }^{2}$ Para o conhecimento do universo vocabular freiriano, em sua profusão neológica, ver o trabalho de Simões (2013). 
de 'endereçar-se' até sonhos, ideais, utopias e objetivos, que se acha o que venho chamando de politicidade da educação" (Freire, 1996/2006, p. 110). E mesmo as reflexões voltadas a tratar do vetor humanista que precisa acompanhar o trabalho junto aos camponeses envolvidos na reforma agrária, expostas em um dos capítulos do livro Extensão ou Comunicação?:

Humanismo, que vendo os homens no mundo, no tempo, "mergulhados" na realidade, só é verdadeiro enquanto se dá na ação transformadora das estruturas em que eles se encontram "coisificados", ou quase "coisificados". Humanismo que, recusando tanto o desespero quanto o otimismo ingênuo, é, por isto, esperançosamente crítico. E sua esperança crítica repousa numa crença também crítica: a crença em que os homens podem fazer e refazer as coisas; podem transformar o mundo. Crença em que, fazendo e refazendo as coisas e transformando o mundo, os homens podem superar a situação em que estão sendo um quase não ser e passar a ser um estar sendo em busca do ser mais. Neste humanismo científico (que nem por isto deixa de ser amoroso) deve estar apoiada a ação comunicativa do agrônomo-educador. (Freire, 1969/1983, p. 50)

Nas próximas seções deste texto, vamos nos concentrar nas três perspectivas que consideramos fundamentais para refletir sobre a influência da obra de Paulo Freire nos estudos e práticas de comunicação: comunicação e educação; comunicação e desenvolvimento da sociedade civil; crítica à comunicação e à mídia.

\section{COMUNICAÇÃO E EDUCAÇÃO}

Não há inteligibilidade que não seja comunicação e intercomunicação e que não se funde na dialogicidade.

-Paulo Freire, Pedagogia da Autonomia

A comunicação é um dos direitos humanos fundamentais. Tal assertiva, em suas formulações e desdobramentos, é encontrada ao longo da obra de Paulo Freire. Desde Extensão ou Comunicação? (Freire, 1969/1983) até a Pedagogia da Autonomia (Freire, 1996/2006), persiste o entendimento de que somos atravessados por "um mundo de comunicação" (Freire, 1969/1983, p. 44). Certamente não se trata de pensar o trânsito comunicacional nos limites das tecnologias ou dos media, senão remetê-lo à vida concreta dos sujeitos na qual se instituem o 
autorreconhecimento e a coparticipação. Daí que todo esforço visando garantir educação, desenvolver programas alfabetizadores, propiciar o crescimento da consciência crítica e buscar a emancipação dos homens e mulheres ganhe potência quando traduzido em matéria compreensiva facultada pelo diálogo entre os sujeitos. Ou ainda: "só se comunica o inteligível na medida em que este é comunicável” (Freire, 1969/1983, p. 46). Tal formulação de singela aparência carrega consigo, ao mesmo tempo, uma perspectiva política e o entendimento de que $\mathrm{o}$ ato de comunicar vai além do simples comunicado, haja vista mobilizar no seu interior a troca de experiências, a reciprocidade comunicante, enfim, a construção do conhecimento:

Conhecer, na dimensão humana, que aqui nos interessa, qualquer que seja o nível em que se dê, não é o ato através do qual um sujeito, transformado em objeto, recebe, dócil e passivamente, os conteúdos que outro lhe dá ou impõe. $\mathrm{O}$ conhecimento, pelo contrário, exige uma presença curiosa do sujeito em face do mundo. Requer sua ação transformadora sobre a realidade. Demanda uma busca constante. Implica em invenção e em reinvenção. Reclama a reflexão crítica de cada um sobre o ato mesmo de conhecer, pelo qual se reconhece conhecendo e, ao reconhecer-se assim, percebe o "como" de seu conhecer e os condicionamentos a que está submetido seu ato. (Freire, 1969/1983, p. 16)

A comunicação surge, portanto, como processo alicerçado nos deslocamentos interindividuais, intersubjetivos, de envolvimento social do sujeito no mundo, dando sentido à vida humana. Em um termo: "as consciências não são comunicantes porque se comunicam; mas comunicam-se porque comunicantes" (Fiori, 1968/2005, p. 15). Afastados da intercomunicação, verbos como educar, alfabetizar, emancipar, libertar, perdem os seus significados fortes, restando como recursos transmissivos de comunicados.

Essa perspectiva freiriana funciona como elemento fertilizador de uma linhagem dos estudos que se desenvolvem em torno das interfaces comunicativas-educativas, ou da educomunicação, segundo terminologia que ganha força entre nós. Aqui não é o lugar para discussão centrada nos alcances, procedimentos, estratégias de ação que envolvem a referida inter-relação. Caberia, neste vetor, examinar desde a entrada dos meios de comunicação na escola, passando pela leitura crítica deles, indo até as dimensões epistemológicas aí envolvidas. A atual crise sanitária resultante da pandemia da covid-19 e a ampliação do uso das tecnologias como estratégia de aula, em modalidades remotas ou híbridas da educação conteria, soi même, temática a ser explorada no âmbito educomunicativo e para a qual o pensamento freiriano aduz importante contribuição. 
É necessário enfatizar que o entendimento de Paulo Freire sobre a comunicação enquanto processo humanizador a leva, diretamente, ao âmbito da educação (entre outros) formal como espaço interativo que requisita pleno exercício do diálogo, portanto, da capacidade de colocar os sujeitos em circuitos de mútuos reconhecimentos, de exercício da alteridade. Assim, o deslocamento das falas, o tensionamento de valores e a admissão do discurso alheio como passível de compor o debate ocorrem ao mesmo tempo que o processo comunicativo se institui, permitindo a circulação do conhecimento.

Depreende-se que a educação como prática da liberdade (circunstância na qual o ato de conhecer não se esgota no objeto conhecido, haja vista criar circuitos comunicativos de respeito a experiências vivenciadas entre os sujeitos cognoscentes) passa ao largo de ser apenas motivo ideológico, slogan ou lema publicístico para se fazer enquanto estrutura democratizante conduzida pelo respeito aos procedimentos formais e valorativos que alimentam o diálogo. A se lembrar que, segundo Paulo Freire (1968/2005), o elemento constitutivo fundamental do diálogo é a palavra marcada por duas faces imantadas, reflexão e ação: "Não há palavra verdadeira que não seja práxis. Daí dizer a palavra verdadeira seja transformar o mundo" (p. 89). A palavra vazia está, por esta via, ao lado dos comunicados, afastando-se do movimento teórico-prático, negando, em última instância, a própria comunicação.

Em nossos termos: o educador dialógico desenvolve a consciência de que reside no comunicável a possibilidade do encontro "dos homens, mediatizados pelo mundo, para pronunciá-lo, não se esgotando, portanto, na relação eu-tu" (Freire, 1968/2005, p. 91). O diálogo se transforma numa exigência para a formação integral dos sujeitos. Com isso, afastamos os pronunciamentos pretextais que fingem elaborar significados partilhados e aderimos à troca efetiva de argumentos, à circulação das ideias, ao reconhecimento democrático de que é possível superar o assimétrico jogo do poder encarnado nos discursos dos grupos dominantes. Em síntese: a comunicação ocorre, efetivamente, quando acontecem as trocas de significados, os vínculos intersubjetivos, a consciência do comum.

Tendo em mira esse horizonte conceitual, prático, valorativo, é imperioso acrescentar que o pensamento freiriano não descurava ou tratava como irrelevante a presença dos dispositivos comunicacionais - segundo os termos de alguém cujo trabalho em diversas frentes precedeu à expansão digital, à internet, malgrado já diante dos computadores e suas funcionalidades correspondentes aos anos 1990. Ocorreu, inclusive, na gestão de Paulo Freire como secretário da educação municipal de São Paulo, a compra de 
um dos primeiros lotes de computadores a serem instalados nas escolas da rede pública da cidade. Sigamo-lo:

Divinizar ou diabolizar a tecnologia ou a ciência é uma forma altamente negativa e perigosa de pensar errado....

Por isso mesmo sempre estive em paz para lidar com ela. Não tenho dúvida nenhuma do enorme potencial de estímulos e desafios à curiosidade que a tecnologia põe a serviço das crianças e dos adolescentes das classes chamadas favorecidas. (Freire, 1996/2006, p. 33, 86)

E chega a recomendar, explicitamente, aos educadores e educadoras progressistas que: "não apenas não podemos desconhecer a televisão, mas devemos usá-la, sobretudo, para discuti-la" (Freire, 1996/2006, p. 139). A despeito de falar do veículo hegemônico no cenário mediático ao tempo, impõe-se reconhecer que estava no escopo de preocupações de Paulo Freire empreender tratamento educativo formal às mensagens comunicacionais dispostas socialmente pela televisão.

Equivale afirmar: a entrada dos meios de comunicação na escola, seja enquanto equipamento ou suporte para ações educativas, seja enquanto produção de mensagens que devem ser analisadas e pensadas sob ótica crítica e reflexiva (em movimentos de retroalimentação no continuum codificação-descodificação), necessita compor o ambiente das salas de aula segundo os propósitos do ensino enquanto prática da liberdade - procedimento que a educomunicação intenta viabilizar na esteira freiriana. É forçoso aludir que o tema da alfabetização midiática, hoje bastante presente nos debates sobre os necessários vínculos comunicação-educação, surge, a seu modo, no projeto intelectual de Paulo Freire, sobretudo nos seus derradeiros escritos, com maior evidência na Pedagogia da Autonomia (Freire, 1996/2006). Cabe lembrar, porém, que, se as literacias expressam condição necessária para o exercício educador em sentido mais amplo, podem não ser elas suficientes. Afinal, segundo defendido ao longo dos anos pelo patrono da educação brasileira, impõe-se desentranhar a cultura do silêncio na qual estão submergidos amplos setores da população. E permitir que a voz dos silenciados (muitas vezes pelos próprios veículos de comunicação, pelo discurso dominante e seus interesses de preservar privilégios, ou, em nossos dias, pelas bolhas da internet) irrompa como elemento ativo nas diversas modalidades comunicacionais - sejam mediadas tecnologicamente, sejam processadas face a face. Assim, alfabetizar-se para os media e as redes sociais é um percurso que não se esgota na identificação das estruturas de linguagem e arranjos codificadores, mas se expande no reconhecimento dos significantes ali ensejados. 
Tal perspectiva abre espaço para que a comunicação seja repensada em dimensão ontológica, ou epistemológica, como preferiria Paulo Freire. Algo essencial nas relações humanas, sem as quais não é possível falar em educação, tampouco buscar a autonomia dos sujeitos. É o que se explicita em Extensão ou Comunicação? (Freire, 1969/1983) e se desdobra no conjunto da obra freiriana: o agrônomo desejoso de passar o seu conhecimento técnico a trabalhadores e trabalhadoras rurais, desconsiderando a realidade na qual vivem; os professores e professoras visualizando no corpo discente apenas as caixas de ressonância de verdades formuladas pela docência; as direções partidárias que formulam palavras de ordem sem ouvir a militância. Tais exemplos explicitam, em recorrente linha de sentido, o fato de negarem o sujeito e a sua autonomia, o que implica, ao fim e ao cabo, romper o processo de comunicação.

\section{UMA COMUNICAÇÃO INSPIRADA EM FREIRE EM PROCESSOS DE MUDANÇA SOCIAL}

Não há, realmente, pensamento isolado na medida em que não há homem isolado.

Todo ato de pensar exige um sujeito que pensa, um objeto pensado, que mediatiza o primeiro sujeito do segundo e a comunicação entre ambos, que se dá através de signos linguísticos.

O mundo humano é desta forma, um mundo de comunicação.

-Paulo Freire, Extensão ou Comunicação?

A associação entre educação, mobilização popular e processos de participação política abre outra perspectiva, que se desdobra na multitude e na diversidade de diálogos e construções que a obra de Freire tem com os movimentos sociais e organizações da sociedade civil em todo o mundo. Nessa perspectiva, o princípio comunicativo da compreensão freiriana sobre a educação se expande para todos os processos em que se propõe a aprendizagem de um novo situar-se no mundo, e mesmo de uma nova configuração do mundo.

Para Freire, a palavra é o elemento gerador da subjetividade e dos agenciamentos sociais. Uma pessoa deixa de ser objeto e passa a ser sujeito da história na medida em que se torna capaz de nomear-se a si mesmo e ao mundo ao seu redor. Esse processo generativo orientado para intervir no mundo e gerar mudança social tornou-se fundamental para o que veio a constituir uma vertente 
significativa dentro da pesquisa e da prática da comunicação - a da comunicação para a mudança social, e muitas vertentes associadas conhecidas sob uma ampla gama de nomes e abordagens, desde a comunicação alternativa na década de 1980 à comunicação popular e comunitária nos anos mais recentes.

Os principais estudiosos do campo da comunicação inspiraram-se nas práticas comunicativas orientadas para a ação de Freire, de Juan Díaz Bordenave, Luis Ramiro Beltrán e Cicilia Peruzzo na América Latina a Frank Gerace, Robert Chambers e muitos outros. Um denominador comum eram os princípios freirianos e seu método, insistindo em não apenas nomear o mundo, mas intervir nele. Juan Díaz Bordenave baseou-se em Freire visando desenvolver sua abordagem de comunicação participativa para a comunicação rural, Frank Gerace escreveu o primeiro livro sobre comunicação horizontal, em 1973, e, em termos mais amplos, várias gerações de profissionais de comunicação e organizações da sociedade civil na América Latina basearam-se no método Paulo Freire em seu trabalho com educação não formal, mobilização e produção midiática, reivindicando direitos humanos e igualdade.

Uma experiência pioneira foi vista no desenvolvimento das Comunidades Eclesiais de Base (CEB), no Brasil e em outros países latino-americanos, nas décadas de 1970 e 1980, uma experiência que visou aproveitar as noções de Freire de comunicação dialógica no sentido de valorizar a subjetividade e a ação social, resistindo, deste modo, à descontinuidade dialógica promovida pelo poder à época. $\mathrm{O}$ autoritarismo que as ditaduras militares impuseram no cone sul constituiu o contexto a que responderam as CEB, inspiradas, também, na Teologia da Libertação. O autor da Pedagogia do Oprimido plantou as sementes de uma nova geração de organizações comunitárias, não governamentais e movimentos sociais. Uma outra perspectiva de articulação de forças na sociedade civil fez-se presente neste quadro, incluindo algumas experiências que, ao longo dos anos, influenciaram as estruturas governamentais - por exemplo, quando Luiza Erundina ganhou a eleição para prefeita em São Paulo, em 1988, e, em 1989, convidou Paulo Freire para se tornar o Secretário Municipal de Educação, que, por sua vez, compôs uma equipe da qual fizeram parte inúmeros ativistas dos movimentos sociais.

Além da América Latina, as ideias de Freire migraram, tanto por meio de seu próprio trabalho global quanto pelos projetos educativos postos em movimento junto aos estados africanos recém-libertos do colonialismo português. Ademais, um número crescente de organizações da sociedade civil adotou as ideias de Paulo Freire, por exemplo, na articulação do método REFLECT (Regenerated Freirean Literacy through Empowering Community Techniques) - desenvolvido no início da década de 1990 por Robert Chambers e a University of Sussex no Reino 
Unido - que se tornou estratégia significativa para o trabalho de Organizações Não Governamentais (ONG) em muitos países da África Subsaariana.

É importante lembrar que o ethos comunicativo da obra de Paulo Freire ganha relevo nesse percurso internacional, haja vista o seu foco na emancipação dos sujeitos, nas relações de igualdade em todas as dimensões do diálogo e das trocas de saberes.

\section{FREIRE E A CRÍTICA À MÍDIA}

Claro está que não residia na adesão de Freire à mobilização dos dispositivos midiáticos nenhuma inocência sobre o papel e o lugar por eles ocupados para ficarmos com a retórica da época - na vida social e, particularmente, no mundo das escolas. Ao contrário, o que existe é uma espécie de visagem pragmática envolvendo a realidade atravessada por mensagens postas em circulação por veículos como a televisão, o rádio, os jornais etc., e que forçosamente estão presentes nas salas de aula, nos ambientes privados de docentes e discentes, nos grupos de amigos dos membros das comunidades escolares.

Como enfrentar o extraordinário poder da mídia, da linguagem da televisão, de sua "sintaxe" que reduz a um mesmo plano o passado e o presente e sugere que o que ainda não há já está feito. ... O mundo encurta, o tempo se dilui: o ontem vira agora; o amanhã já está feito. Tudo muito rápido. Debater o que se diz e o que se mostra e como se mostra na televisão me parece algo cada vez mais importante. (Freire, 1996/2006, p. 141)

Dessas e de outras passagens em seu trabalho, pode-se entender que não há, propriamente, uma crítica ao desenvolvimento midiático, mas, novamente, é essencial a presença de um educador militante contrário aos usos massivos, deterministas e opressivos de toda e qualquer plataforma de comunicação. Em uma entrevista, Paulo Freire insiste sobre a falta de "uma decisão política que ponha os meios também a serviço das classes populares" (Fadul, 1987, p. 90). Nessa conversa, ele se opõe a usos dos meios que buscam a cooptação das audiências, em crítica semelhante a que faz à educação bancária. Ou seja, existe declarada condenação a esquemas verticais de transmissão de informações que se fazem longe dos procedimentos dialógicos e da autonomia de pensamento.

Nessa entrevista, quando Anamaria Fadul (1987) provoca o nosso educador

para discorrer sobre a defasagem entre o desenvolvimento do sistema de educação e do sistema de comunicação no Brasil, ele revela duas preocupações complementares. 
A primeira faz referência à presença de um sistema de comunicação predatório e elitista, em que as classes populares só aparecem como "objeto de estranheza" (p. 90); e a segunda está associada à necessidade de criar uma dinâmica educativa capaz de produzir cidadãos e cidadãs críticos/as ao enunciado na referência primeira. Em linhas gerais, a visão de Freire acerca do sistema de comunicação contemplava o acesso amplo e irrestrito aos media, ao mesmo tempo que trazia à tona a necessidade de que fossem pensados criticamente:

Não temo parecer ingênuo ao insistir não ser possível pensar sequer em televisão sem ter em mente a questão da consciência crítica. É que pensar em televisão ou na mídia em geral nos põe o problema da comunicação, processo impossível de ser neutro. ... Daí também o papel apurado que joga a ideologia na comunicação, ocultando verdades, mas também a própria ideologização no processo comunicativo. (Freire, 1996/2006, p. 141)

Tais ideias ajudaram a delinear uma lacuna que movimentos sociais trataram de preencher com diferentes estratégias. Entre os expoentes dessa abordagem, estão obras como Para leer al Pato Donald, de Ariel Dorfman e Armand Mattelart, de 1971, e amplos programas de capacitação em Leitura Crítica da Comunicação (LCC), como os realizados pela União Cristã Brasileira de Comunicação Social (UCBC), entre as décadas de 1970 e 1990. O livro de Dorfman e Mattelart é considerado um dos trabalhos pioneiros dos estudos culturais na América Latina. Sua crítica marxista à propaganda capitalista e ao imperialismo cultural dialoga abertamente com a perspectiva de Freire, segundo a qual "o oprimido tem uma outra leitura das mensagens veiculadas. Não há adesão sem resistência" (Fadul, 1987, p. 92). Assim, apesar de reconhecer o esforço de cooptação das classes populares, havia uma confiança na sua capacidade crítica e reativa de apropriação das mensagens midiáticas.

Nessa esteira, programas como os organizados pela UCBC se espalharam pela América Latina. Entre seus objetivos estava desmistificar o sistema de comunicação, alertar para as colisões político-econômicas nesse sistema e oferecer ferramentas para ampliar a capacidade crítica de cidadãos e cidadãs em relação ao consumo de mídia. Havia também interesse em promover a produção autônoma de comunicação a partir das próprias comunidades e organizações nas bases.

Os cursos de LCC passaram a ter um perfil de conferências, com debates posteriores, sobre o sistema de comunicação, a indústria cultural, as contradições do desempenho dos meios de comunicação de massa, os excessos cometidos por esses veículos, 
enquanto informadores da opinião pública, etc. A estes temas, acrescentava-se um estudo da comunicação cristã e do próprio culto ou liturgia praticada pelas comunidades cristãs. O objetivo era denunciar a manipulação exercida pelos meios de comunicação de massa e alertar sobre os responsáveis pelo controle e desvio da informação: o próprio sistema sóciopolítico-econômico-cultural vigente no Brasil e, em geral, no mundo. Os cursos procuravam apontar pistas de ação, principalmente orientando para o exercício da comunicação alternativa e popular. (União Cristã Brasileira de Comunicação Social, 1985, p. 6)

Finalmente, consciente do poder desigual dos meios massivos de comunicação, Freire tampouco se abstinha de um compromisso com a presença nesses espaços. Em outro trecho de sua entrevista dada a Anamaria Fadul (1987), ele discorre sobre a necessidade de ocupá-los, em um horizonte compartilhado, historicamente, com muitos movimentos sociais.

Por outro lado, quero deixar claro que se não é possível por a TV a serviço da classe trabalhadora, cabe a nós com muito mais dificuldade que no caso da educação, invadir o espaço da TV. Quanto as TVs me convidam para participar de programas nunca recuso, desde que seja ao vivo, porque esta é uma tarefa política, usar um tempo em um espaço que não é meu. (p. 92)

Nesse passo, é oportuno lembrar que a contemporânea difusão das fake news, das informações maliciosas, do negacionismo, da intolerância, em parte distribuída por redes (in)sociais, mas de acesso avassalador por parte dos segmentos escolares, pode ser combatida no âmbito da educação formal com um programa freiriano de elevação da capacidade de discernir, da intercomunicação que suscita o juízo crítico, da inflexão emancipatória de docentes e discentes. Em um termo: é necessário localizar a comunicação como centro do ato comunicante, algo que institui a comunicabilidade - através dos signos, das linguagens complexas, das palavras não burocratizadas que apenas distribuem comunicados - "que se faz e que se vive enquanto dela se fala com a força do testemunho" (Freire, 1996/2006, p. 37).

Esses esforços de colocar a comunicação no centro de um processo libertador constituem uma luta frequentemente travada para além do setor educacional formal, nos espaços dialógicos criados pela sociedade civil nas ONG, nas associações comunitárias e na multiplicidade de movimentos sociais que caracterizam o nosso tempo. Todas essas instituições, organizações e movimentos reivindicam estar presentes nos diálogos que definem o nosso futuro e, ao fazê-lo, prestam a sua mais forte homenagem a Paulo Freire. 


\section{CONSIDERAÇÕES FINAIS}

Os artigos reunidos nesse número especial de MATRIZes, por vias diferentes e ponderações múltiplas, situam o percurso freiriano em sua amplitude teórico-prática, acentuando, sobretudo, os temas da comunicação e as suas interfaces. No propósito de organizá-los, ao menos aproximadamente, agrupamo-los em quatro grandes eixos temáticos passíveis de interconexões quando remetidos à obra de Paulo Freire: comunicação para além dos comunicados; comunicar e educar; comunicação e desdobramentos culturais; comunicação: recortes políticos e mudanças sociais.

MATRIZes agradece aos autores e autoras nacionais e internacionais que aceitaram participar desta homenagem a Paulo Freire.

Boa leitura. M

\section{REFERÊNCIAS}

Downing, J. D., Ford, T. V., Gil, G., \& Stein, L. (2001). Radical media: Rebellious communication and social movements. Sage.

Fadul, A. (1987). Paulo Freire: Educação e comunicação ou o difícil caminho da liberação. Diálogos de la Comunicación, (18), 86-92. https://bit.ly/3CvnAeg

Fiori, E. M. (2005). Aprender a dizer a sua palavra. In P. Freire, Pedagogia do oprimido (42a ed., pp. 7-22). Paz e Terra. (Trabalho original publicado em 1968)

Freire, P. (1983). Extensão ou comunicação? Paz e Terra. (Trabalho original publicado em 1969)

Freire, P. (2005). Pedagogia do oprimido (42a ed.). Paz e Terra. (Trabalho original publicado em 1968)

Freire, P. (2006). Pedagogia da autonomia (33a ed.). Paz e Terra. (Trabalho original publicado em 1996)

Furter, P. (1967). Paulo Freire ou O poder da palavra. In P. Freire, Educação como prática da liberdade (orelha). Paz e Terra.

Gumucio-Dagron, A., \& Tufte, T. (Eds.). (2006). Communication for social change anthology: Historical and contemporary readings. Communication for Social Change Consortium.

Peruzzo, C. M. K. (2020a). Paulo Freire's role and influence on the praxis of popular communication in Brazil. International Communication Gazette, 82(5), 425-439. https://doi.org/10.1177/1748048520943693

Peruzzo, C. M. K. (2020b). Popular and communitarian communication in rural social movements: Beyond "diffusionism" to emancipatory participation. In A. C. Suzina (Ed.), The evolution of popular communication in Latin America: An epistemology of the south from media and communication studies (pp. 51-71). Palgrave. 
Rodríguez, C. (2001). Fissures in the mediascape: An international study of citizen's media. Hampton Press.

Simões, S. L. (2013). Pedagogia do neologismo: A linguagem de Paulo Freire e a educação libertadora [Tese de doutorado, Universidade Nove de Julho]. Biblioteca Digital de Teses e Dissertações da Uninove. https://bit.ly/3kTy7dg

Suzina, A. C. (Ed.). (2021). The evolution of popular communication in Latin America: An epistemology of the south from media and communication studies. Palgrave Macmillan.

Tufte, T. (2017). Communication for social change: A citizen perspective. Polity. União Cristã Brasileira de Comunicação Social. (1985). Projeto LCC: A história de um processo. UCBC. 


\section{PARECERISTAS DE 2021}

Adilson Citelli - Universidade de São Paulo, Brasil

Adriana Amaral - Universidade do Vale do Rio dos Sinos, Brasil

Alexandre Rocha da Silva - Universidade Federal do Rio Grande do Sul, Brasil

Alisson Machado - Universidade Federal de Santa Maria, Brasil

Álvaro Larangeira - Universidade Tuiuti do Paraná, Brasil

Ana Cláudia Niedhardt Capella - Universidade Federal de São Carlos, Brasil

Ana Cristina Suzina - Loughborough University London, Reino Unido

Ana Javes Luz - Universidade Federal do Rio Grande do Sul, Brasil

Antonio Teixeira de Barros - Centro de Formação Política da Câmara dos Deputados, Brasil

Arthur Ituassu - Pontifícia Universidade Católica do Rio de Janeiro, Brasil

Atílio José Avancini - Universidade de São Paulo, Brasil

Ben-Hur Demeneck - Universidade de São Paulo, Brasil

Benjamim Picado - Universidade Federal Fluminense, Brasil

Bernardo Estellita Lins - Universidade de Brasília, Brasil

Beth Brait - Universidade de São Paulo, Brasil

Bruno Paes Manso - Universidade de São Paulo, Brasil

Camila Moreira Cesar - Université Sorbonne Nouvelle Paris 3, França

Carina Ochi Flexor - Universidade de Brasília, Brasil

Carlos d'Andréa - Universidade Federal de Minas Gerais, Brasil

Carlos Eduardo Marquioni - Universidade Tuiuti do Paraná, Brasil

Cássio dos Santos Tomaim - Universidade Federal de Santa Maria, Brasil

Catarina Duff Burnay - Universidade Católica Portuguesa, Portugal

Ceiça Ferreira - Universidade Estadual de Goiás, Brasil

Celbi Vagner Melo Pegoraro - Universidade de São Paulo, Brasil

Cíntia Sanmartin Fernandes - Universidade do Estado do Rio de Janeiro, Brasil

Clarice Greco - Universidade Paulista, Brasil

Cleber Santos Vieira - Universidade Federal de São Paulo, Brasil

Clotilde Perez - Universidade de São Paulo, Brasil

Cristiane Brum Bernardes - Instituto Nacional de Ciência e Tecnologia em

Democracia Digital, Brasil

Cristina Teixeira Vieira de Melo - Universidade Federal de Pernambuco, Brasil

Daniel Meirinho - Universidade Federal do Rio Grande do Norte, Brasil

Danilo Rothberg - Universidade Estadual Paulista Júlio de Mesquita Filho, Brasil

Diego Gouveia Moreira - Universidade Federal de Pernambuco, Brasil

Dimas A. Künsch - Universidade Metodista de São Paulo, Brasil

Dora Kaufman - Pontifícia Universidade Católica de São Paulo, Brasil

Eduardo Georjão Fernandes - Universidade Federal de Pelotas, Brasil 
Eduardo Zilles Borba - Universidade Federal do Rio Grande do Sul, Brasil Eli Borges Junior - Universidade de São Paulo, Brasil

Eliane Hatherly Paz - Universidade Federal do Rio de Janeiro, Brasil

Elias Cunha Bitencourt - Universidade do Estado da Bahia, Brasil

Eliza Bachega Casadei - Escola Superior de Propaganda e Marketing - SP, Brasil

Eugenio Bucci - Universidade de São Paulo, Brasil

Fábio Henrique Pereira - Universidade de Brasília, Brasil

Fábio Palácio de Azevedo - Universidade Federal do Maranhão, Brasil

Fabíola Calazans - Universidade de Brasília, Brasil

Fabrício Lopes da Silveira - Universidade Federal do Rio Grande do Sul, Brasil Fátima Régis Oliveira - Universidade do Estado do Rio de Janeiro, Brasil

Felipe Corrêa de Mello - Escola Superior de Propaganda e Marketing - SP, Brasil

Felipe de Castro Muanis - Universidade Federal de Juiz de Fora, Brasil

Fernanda Martinelli - Universidade de Brasília, Brasil

Fernando Simões Antunes Junior - Universidade Feevale, Brasil

Filipa Brito Subtil - Instituto Federal de Lisboa, Portugal

Flavi Ferreira Lisboa Filho - Universidade Federal de Santa Maria, Brasil

Flávia Biroli - Universidade de Brasília, Brasil

Flávia Garcia Guidotti - Universidade Federal de Santa Catarina, Brasil

Flávio Augusto Queiroz e Silva - Pontifícia Universidade Católica de São Paulo, Brasil Flora Daemon - Universidade Federal Rural do Rio de Janeiro, Brasil

Florence Marie Dravet - Universidade Católica de Brasília, Brasil

Francisco Paulo Jamil Almeida Marques - Universidade Federal do Paraná, Brasil Francisco Rüdiger - Pontifícia Universidade Católica do Rio Grande do Sul, Brasil Gianlluca Simi - University of Nottingham, Reino Unido

Gilson Schwartz - Universidade de São Paulo, Brasil

Glauco Madeira de Toledo - Centro Universitário Nossa Senhora do Patrocínio, Brasil Gustavo Chataignier - Pontifícia Universidade Católica do Rio de Janeiro, Brasil Gustavo Daudt Fischer - Universidade do Vale do Rio dos Sinos, Brasil

Helena Nagamine Brandão - Universidade de São Paulo, Brasil

Helton Levy - John Cabot University, Itália

Ieda Tucherman - Universidade Federal do Rio de Janeiro, Brasil

Inesita Soares de Araújo - Fundação Oswaldo Cruz, Brasil

Ione Maria Ghislene Bentz - Universidade do Vale do Rio dos Sinos, Brasil

Isabel Maria Ribeiro Ferin Cunha - Universidade de Coimbra, Portugal

Ivan Vasconcelos Figueiredo - Universidade Federal de São João del-Rei, Brasil

Jiani Adriana Bonin - Universidade do Vale do Rio dos Sinos, Brasil

Joanise Levy - Universidade Estadual de Goiás, Brasil

Jorge Cardoso Filho - Universidade Federal do Recôncavo da Bahia, Brasil 
Jorge Kanehide Ijuim - Universidade Federal de Santa Catarina, Brasil

Jorge Luis Rodrigues dos Santos - Universidade Federal do Estado do Rio de Janeiro, Brasil

José Luiz Warren Jardim Gomes Braga - Universidade do Vale do Rio dos Sinos, Brasil

Juliana Gagliardi - Universidade do Estado do Rio de Janeiro, Brasil

Juliano Silva Borges - Faculdades Ibmec Rio de Janeiro, Brasil

Julio Cesar Lemes de Castro - Universidade de São Paulo, Brasil

Karliane Macedo Nunes - Universidade Federal do Amazonas, Brasil

Krystal Cortez Luz Urbano - Universidade Federal Fluminense, Brasil

Laura Hastenpflug Wottrich - Universidade Federal do Rio Grande do Sul, Brasil

Leandro Rodrigues Lage - Universidade da Amazônia, Brasil

Leo Mozdzenski - Universidade Federal de Pernambuco, Brasil

Leonardo De Marchi - Universidade Federal do Rio de Janeiro, Brasil

Leonardo Gomes Esteves - Universidade Federal de Mato Grosso, Brasil

Leonardo Pastor - Universidade Federal da Bahia, Brasil

Leticia Cantarela Matheus - Universidade do Estado do Rio de Janeiro, Brasil

Lorena Rúbia Pereira Caminhas - Universidade Estadual de Campinas, Brasil

Lucas Correia Meneguette - Universidade Federal da Bahia, Brasil

Lúcia Lamounier Sena - Pontifícia Universidade Católica de Minas Gerais, Brasil

Lucia Santa Cruz - Escola Superior de Propaganda e Marketing - RJ, Brasil

Luciana de Oliveira - Universidade Federal de Minas Gerais, Brasil

Luciana Panke - Universidade Federal do Paraná, Brasil

Lucrécia D’Aléssio Ferrara - Pontifícia Universidade Católica de São Paulo, Brasil

Luis Mauro Sa Martino - Faculdade Cásper Líbero, Brasil

Luiz Antonio Mousinho Magalhães - Universidade Federal da Paraíba, Brasil

Luiz Peres-Neto - Universitat Autònoma de Barcelona, Espanha

Marcio Acselrad - Universidade de Fortaleza, Brasil

Magaly Parreira Prado - Universidade de São Paulo, Brasil

Mara Rovida - Universidade de Sorocaba, Brasil

Marcel Vieira Barreto Silva - Universidade Federal da Paraíba, Brasil

Marcelo Trasel - Universidade Federal do Rio Grande do Sul, Brasil

Marcia Benetti - Universidade Federal do Rio Grande do Sul, Brasil

Márcia Gomes Marques - Universidade Federal de Mato Grosso do Sul, Brasil

Marcia Perencin Tondato - Escola Superior de Propaganda e Marketing - SP, Brasil

Marcius Freire - Universidade Estadual de Campinas, Brasil

Marcos Paulo da Silva - Universidade Federal de Mato Grosso do Sul, Brasil

Maria Ataide Malcher - Universidade Federal do Pará, Brasil

Maria Cristina Castilho Costa - Universidade de São Paulo, Brasil 
Maria Gislene Carvalho Fonseca - Universidade Federal de Ouro Preto, Brasil Maria Ignes Carlos Magno - Universidade Anhembi Morumbi, Brasil

Mariana Baltar - Universidade Federal Fluminense, Brasil

Mario Abel Bressan Junior - Universidade do Sul de Santa Catarina, Brasil

Marta Gouveia de Oliveira Rovai - Universidade Federal de Alfenas, Brasil

Marta Regina Maia - Universidade Federal de Ouro Preto, Brasil

Mayka Castellano - Universidade Federal Fluminense, Brasil

Melina Meimaridis - Universidade Federal Fluminense, Brasil

Michelle Bonner - University of Victoria, Canadá

Mozahir Salomão Bruck - Pontifícia Universidade Católica de Minas Gerais, Brasil

Myrian Regina Del Vecchio de Lima - Universidade Federal do Paraná

Nina Santos - Universidade Federal da Bahia, Brasil

Otávio Daros - Pontifícia Universidade Católica do Rio Grande do Sul, Brasil

Patrick Ciarelli - Universidade Federal do Espírito Santo, Brasil

Paulo Roberto Figueira Leal - Universidade Federal de Juiz de Fora, Brasil

Paulo Serra - Universidade da Beira Interior, Portugal

Rafael Alonso - Universidade Federal de Santa Catarina, Brasil

Rafael Foletto - Universidade Federal de Santa Maria, Brasil

Rafael José Bona - Universidade Regional de Blumenau; Universidade do Vale do Itajaí, Brasil

Rafael Tassi Teixeira - Universidade Tuiuti do Paraná, Brasil

Rafiza Luziani Varão Ribeiro Carvalho - Universidade de Brasília, Brasil

Regina Cazzamatta - Universität Erfurt, Alemanha

Reinaldo Maximiano Pereira - Universidade Federal de Uberlândia, Brasil

Renato Luiz Pucci Junior - Universidade Anhembi Morumbi, Brasil

Richard Romancini - Universidade de São Paulo, Brasil

Rodrigo Carreiro - Universidade Federal de Pernambuco, Brasil

Rodrigo Fontanari - Universidade Estadual de Campinas, Brasil

Rogério Christofoletti - Universidade Federal de Santa Catarina, Brasil

Ronivaldo Moreira de Souza - Universidade Paulista, Brasil

Rosana de Lima Soares - Universidade de São Paulo, Brasil

Sílvio Antonio Luiz Anaz - Universidade de São Paulo, Brasil

Silvio Santos - Universidade de Coimbra, Portugal

Sônia Meneses - Universidade Regional do Cariri, Brasil

Sylvia Beatriz Bezerra Furtado - Universidade Federal do Ceará, Brasil

Sylvia Iasulaitis - Universidade Federal de São Carlos, Brasil

Tadeu Rodrigues Iuama - Universidade de Sorocaba, Brasil

Thales Vilela Lelo - Universidade de São Paulo, Brasil

Thiago Falcão - Universidade Federal da Paraíba, Brasil 
Thomas Tufte - Loughborough University London, Reino Unido

Tiago Barcelos Pereira Salgado - Pontifícia Universidade Católica de Minas Gerais, Brasil

Tomaz Affonso Penner - Universidade de São Paulo, Brasil

Valdecir Becker - Universidade Federal da Paraíba, Brasil

Valdenise Lézier Martyniuk - Pontifícia Universidade Católica de São Paulo, Brasil

Valéria Maria Vilas Bôas - Universidade Federal de Sergipe, Brasil

Vera Gasparetto - Universidade Federal de Santa Catarina, Brasil

Vilso Junior Santi - Universidade Federal de Roraima, Brasil

Virginia Pradelina da Silveira Fonseca - Universidade Federal do Rio Grande do Sul, Brasil

Vitor Souza Lima Blotta - Universidade de São Paulo, Brasil

Wagner Souza e Silva - Universidade de São Paulo, Brasil 